ELSA CECILIA FROST

\title{
El Guadalupanismo*
}

\begin{abstract}
ClANDO un culto tiene, como el guadalupano, más de a cuatrocientos cincuenta años de existencia, posec tambien, por esc moro becho, una bibliogralia tan abundante que resulta inmancjable. No queda, por tanto, sino cortar por lo samo y clegir uno de los muchos, muchisimos aspectos de tal culco y procurar enfocarlo de tal modo que la exposición no sea una simple repetición de lo dicho por otros. En cl caso parlicular del guadalupanismo hay libros básicos que deben ser leidos por todos los interesados en el tema y que me he permitido agregar al final del cnsayo.

Tales obras y muchisimas más han sido cditadas y reeditadas muchas veces y son accesibles de un modo $u$ otro a cualquier interesado. Por lo tanto, sólo me referiré a cllas de modo tangencial, centrándome en la actitud que dos de las grandes órdences misioneras de la Nueva España -franciscanos y jesuitas- mantuvieron durante los siglos XVI a XVIII frente al cul(o) guadalupano.

Hacia lines del siglo XVI, un fiaile fianciscano que luera misionero, excelente nahuatlaco, autor de comedias o "ejemplos" para los indigenas, guardián de varios conventos de su orden, constructor de cal\%adas y de la iglesia de Santiago Tlateloleo y que aun habria de ser provincial de los frailes menores, fiay Juan de Torquemada, en suma, inició la redacción de una obra voluminosa, eruditisima, pensada y, es preciso recono-
\end{abstract}

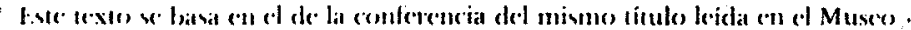

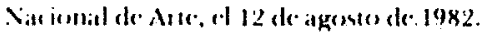


cerlo, en ocasiones deliciosa, que recibió el nombre de Los veintiü libros rituales y monarquia indiana. Crónica que, por lo demás, había de ser hasta época relativamente reciente, la única publicada de entre las muchas escritas por franciscanos. ${ }^{1}$

Pues bien, en esta obra aparecen tres pequeños textos en los que se hace referencia al Tepeyac. El primero se encuentra en el libro II, cap. 3, donde al hablar de la peregrinación de los mexicas se identifica "Tepeyac" mediante la adición de las palabras: "donde es ahora Nuestra Señora de Guadalupe". Lo mismo sucede en el libro IV, cap. 67, donde la identificación es entre "Tepeaquilla" y Nuestra Señora de Guadalupe. El cambio de nombre de Tepeyacac a Tepeaquilla no debe sorprender, ya que este capítulo se refiere a las vicisitudes de Cortés tras la derrota de Narváez, y fray Juan utiliza sencillamente ê nombre castellanizado que desde entonces se daba al lugar.

Llegamos, por fin, al tercer texto sobre el Tepeyac:

En esta Nueva España tenían estos indios gentiles tres lugares, en los cuales honraban tres dioses diversos y les celebraban fiestas: el uno de los cuales está en las faldas de la sierra grande, que se llaina Tlaxcallan... En este lugar hacían fiesta a la diosa llamada Toci, que quiere decir "nuestra abuela". En otro lugar... que se llama Tianquizmanalco ... hacían fiesta a un dios que le llamaban Telpuchtli, que quiere decir "mancebo". Y en otro que está a una legua de esta ciudad de México, a la parte. norte, hacían fiesta a otra diosa, llamada Tonan, que quiere decir "nuestra madre", cuya devoción de dioses prevalecía cuando nuestros frailes vinieron a esta tierra... Pues queriendo remediar este gran daño nuestros primeros religiosos; que fueron los que primero que otros entraron a vendimiar esta viña inculta y a podarla, para que sus renuevos y pámpanos hechasen fruto para Dios, determinaron de poner iglesia y templo en la falda de la dicha sierra de Tlaxcallan, en un pueblo que se llama Chiauhtempa ... y en ella conștituyeron a la gloriosísima Santa Ana, abuela de Nuestro Señor, porque viniese con la festividad antigua, en lo que toca a la gloriosa celebración de su día, aunque no en el abuso y celebración idolátrica. En Tianhuizmanalco constituyeron casa San Juan Bautista; y en Tonantzin, junto a México, a la Virgen sacratísima, que es nuestra Señora y Ma-

1 Editada por primera vez en Sevilla en 1615 y después en Madrid en 1723: 
dre; y en estos tres lugares se celebran estas tres festividades, a las cualès concurren las gentes, en especial a la de San.Juan; y hay muy grandes ofrendas aunque la mayor devoción ha faltado. ${ }^{2}$

Si analizamos este texto, pớr demás escueto, de Torquemada, hay algo que llama de inmediató la atención y és la suscitución deliberada del culto a tres deidades indígenas por lo que pudiera llamarse su contrapartida cristiana: el de Toci, "nuestra abuela", por el de Santa Ana, "abuela del Señor"; el de Telpuchtli, el "mancebo", por el de San Juan Bautista, y por último el de Tonan, "nuestra madre", por el de la Virgen, "nuestra Señora y Madre".

El hecho de que tal medida se atribuya a los primeros misioneros, cosa que no se dice en ninguna otra crónica, hace pensar en una escisión dentro del grupo franciscano, como espero que se probará a continuación. Todo el párrafo tiene un tono de disculpa y la frase que lo cierra, "la mayor devoción ha faltado", que fray Juan atribuye a diversas causas, deja traslucir una cierta amargura y también cierta oposición a tal práctica. Aunque quizá le ençuentre yo estas características influida por un texto franciscano anterior, éste del insigne fray Bernardino de Sahagún, que bien pudo ser la fuente de Torquemada, y que resulta abiertamente contrario al culto guadalupano. Sahagún, después de hacer referencia a tres o cuatro santuarios indigenas, dice a la letra:

El uno de éstos es aquí en México, donde está un montecillo que se llama Nuestra Señora de Guadalupe; en este lugar tenian un templo dedicado a la madre de los dioses que llamaban Tonantzin, que quiere decir "nuestra madre"; alli hacían muchos sacrificios en honor a esta diosa, y venían a ellos de muy lejanas tierras ... y ahora que está alli edificada la iglesia de Nuestra Señora de Guadalupe también la llaman Tonantzin, tomada la ocasión de los predicadores que a nuestra Señora la Madre de Dios la llaman Tonantzin ... sabemos de cierto que el vocablo significa en su primera imposición a aquella Tonantzin antigua y es cosa que se debía remediar porque el propio nom-

2. Monarquia indiana, libro X, cap. 7. 
bre de la Madre de Dios Señora Nuestra no es Tonantzin, sino Dios y Nantzin; parece ésta invención satánica para paliar la idolatria debajo de la equivocación de este nombre.

La devoción también resulta "sospechosa" porque si bien hay muchas iglesias dedicadas a María, los indigenas prefieren ésta. Fray Bernardino la emprende enseguida con los otros dos santuarios, el de Toci y el de Telpuchtli, y también contra sus hermanos de hábito que han permitido la permanencia del vocablo indigena y aun lo han usado en el púlpito cuando lo que debieron o deberán hacer es mostrar a los indios el

cugaño que padecen, dándoles a entender aquellos días que allí viencon la lisisedact antigua, y que no es aquélla conforme a la antigua, y csto deberían hacer predicadores bien entendidos en $l_{\text {iq }}$ lengua y costumbres antiguas que ellos tenían y también en la r.scritura divina. ${ }^{3}$

La indignación del buen fraile es evidente, como lo es lambién la división de pareceres entre los primeros evangelizadores.

Pero si estos párrafos parecen duros, aún hay que añadir orro, tomado de las Informaciones que hubieron de hacerse con ocasión del escándalo provocado por un sermón del provincial fianciscano. Este se atrevió a denunciar durante la misa del 8 de septiembre de 1556 al propio fray Alonso de Montúfar, arzobispo de la no muy tranquila ciudad de México, por el sermón que su Ilustrísima había pronunciado el día 6 del mismo mes y en el que incitó a los habitantes de la ciudad a un mayor guadalupanismo. No bien enterado de ello, fray Francisco de Bustamante, que tal era el nombre del provincial, aprovechó la primera oportunidad para afirmar -según dice un visitador olicial-que si bien no quería contradecir al arzobispo, ni hacer que ninguna viejecita perdiese la devoción, el culto guadalupano

cra cosa perniciosa para los naturales de esta tierra, porque /los misioneros/les habían dado a entender en sus sermones que las

3 Fray Bcrnaidino de Sahagún, Historia general de las cosas de Nueva España, 4 vols., Mexico, Ed. Porrúa, 1977, libro XI, cap. 12, apéndice: "Adición sobre supersticiones", vol. III, p. 352-354. 
imágenes eran de palo y de piedra y que no se habian de adorar, mas que estaban por semejanza de las del cielo, y que los indios eran tan devotos de Nuestra Señora que la adoraban y que pasaban mucho trabajo para quitarles aquella opinión, y que visto ahora que aquella imagen hacía milagros, aunque no estaba ninguno averiguado, que se pasaría mucho trabajo de aqui en adelante en quitarles fa opinión que tenían de adorar la imagen de Nuestra Señora. ${ }^{4}$

Debo advertir que, por tajante que parezca este texto, es la versión más ecuánime; las dos denuncias y las declaraciones de los testigos atribuyen al padre Bustamante expresiones aún más fuertes. Para su análisis hagamos a un lado el hecho del enfrentamiento entre el arzobispo y el provincial de una orden, ya que esto fue ocurrencia cotidiana durante aquel tiempo. Fijémonos en cambio en que fray Francisco no hace mención de los españoles - a los que sí se había referido Montúfar- y centra toda su indignación en el daño que se está haciendo a los naturales, lo mismo que Sahagún y también que Torquemada. En general, los franciscanos no se preocupan por los españoles, puesto que son cristianos viejos o deberían serlo. Su celo se dirige exclusivamente a defender al indigena de lo que consideran un gran peligro: ni más ni menos que el sincretismo.

Pero si recordamos que tanto Sahagún como Torquemada habían atribuido el origen del culto a la acción imprudente de algunos religiosos de su misma orden (sea por haberlo iniciado, sea por permitirlo), acción respaldada, según Bustamante, por la propia jerarquía eclesíastica, veremos que la escisión entre los franciscanos, antes mencionda como algo posible, es un hecho.

Así pues, para resolver la ambigüedad de la actitud franciscana ante este culto, habrá que tener en cuenta las características del grupo misionero. Desde luego, en cualquier circunstancia y por mucho que sea el cuidado que se tenga al hacer la elección, no es posible lograr un grupo verdaderamente homogéneo y aquí nos encontramos claramente con un sector

${ }^{4}$ Fray Fidel de Jesús Chauvet, El culto guadalupano del Tepeyac, México, Centro de Estudios Fray Bernardino de Sahagún, 1978, reproduce esta Información, p. 213-215, el texto citado aparece en la página 218. 
-aparentemente minoritario-de franciscanos que no vio, llevado por su entusiasmo ante la rapidísima conversión de los indígenas, el peligro de que tal conversión no fuera plena. Se trataba - hagamos hincapié en ello- de evangelizar a toda una sociedad y no a individuos, y por ello se podía ser un tanto laxo. Después de todo, habría mucho tiempo para perfeccionar y afianzar lo que apenas se iniciaba.

Se quiso, pues, cortar con la idolatría y ¿qué mejor modo de mostrar el poder de Dios que establecer su templo sobre las ruinas del santuario indígena? Hasta aquí, la política de los dos grupos franciscanos no difiere; lo grave -tanto para Sahagún como para Bustamante- es que se diese a la iglesia una advocación que permitiera una fácil sustitución, pero también una fácil confusión, entre la deidad prehispánica y un santo cristiano. Dado que los textos que atacan esta práctica callan los nombres de los iniciadores de ella, resulta ahora imposible scinalarlos. Quizá se trate de aquellos misioneros que -por su edad o por cualquier otra causa - fueron incapaces de aprender las lenguas indigenas y, por ello mismo, no vieron el peligro de sincretismo implícito en su acción. Pero quizá hubo algo más que desconocimiento o imprudencia, dado que en los tres casos citados, la elección de la advocación cristiana se amolda perfectamente al tipo de deidad antes adorado en ese lugar.

Pero pasemos ahora al otro grupo franciscano, que he llamado mayoritario sin más motivo que el hecho de que pertenezcan a cl todos los grandes misioneros del siglo XVI de quiences queda aún algún escrito: Zumárraga, Motolinía, Olmos, Sahagún. Molina, Mendieta, Torquemada. Para estos hombres, la evangelización de los indios -sin duda alguna, de masas- debia hacerse en una forma elemental, pero por ello mismo muy sólida. Para conseguir su fin, utilizaron el método que se ha denominado de tabula rasa, es decir, borrar lo más radicalmente posible cualquier vestigio de una religión que veian como demoníaca. A ello y no a otra cosa obedecieron las quemas de códices y antiguallas de los indios ordenadas por el obispo Zumárraga. Y el temor al sincretismo fue tan grande que llevó a Olmos y Sahagún a explorar a la mayor profundidad posible el alma de los neófitos; y si dejaron constancia de 
los usos y costumbres precortesianos, no fue movidos por una pasión etnográfica, sino por el celo del médico que quiere extirpar de raíz toda la enfermedad.

Con todo, hay un punto en el cual ambos grupos parecerían estar de acuerdo que es, precisamente, el de los santuarios. Si conforme a la idea arriba apuntada, la religión indígena era invento y manifestación clarísima del demonio, lo primero que debía hacerse era exorcizar la tierra. Por ello, como dice Motolinia, "hicieron altas y grandes cruces, a las cuales adoraban, y mirando sanaban algunos que aún estaban heridos de la idolatría. Otros muchos con esta santa señal fueron librados de diversas asechanzas y visiones que se les aparecían". Y añade, más adelante, que en Tezcoco "adonde había los más y mayores teocallis o templos del demonio" y en México, Cuautitlán y "casi a la par en Tlaxcallan comenzaron a derribar y destuir ídolos y a poner la imagen del crucifijo"..5 Pero como bien conocían los frailes la malicia de los indios "que como tenían cien dioses, querían tener ciento y uno", los obligaron a construir iglesias si querían que los frailes les diesen "imágenes de Dios o de Santa María".

Vale la pena detenerse en este párrafo de Motolinía, pues en él se presentan dos características fundamentales de la labor apostólica de este grupo: una fe inconmovible en que el poder de Dios acabará con la idolatría y una evidente renuencia a presentar a la Madre de Dios en una advocación determinada. De hecho, si se analizan estas crónicas junto con los catecismos y manuales de confesores, lo mismo que con las comedias inventadas para edificación de los indios, llama la atención de inmediato la ausencia casi total de cualquier referencia a los santos y el hecho de que todos estos escritos giren en su mayoría en torno a la vida de Cristo. Entiéndase, no se trata de que estos franciscanos nieguen el papel de María, o de los santos, e incurran en un luteranismo que les era totalmente ajeno, sino de que su predicación es siempre cristocéntrica. ¿ Por qué? La respuesta no es fácil, pero recuérdese que si las órdenes medicantes fueron elegidas pra la evangelización de las nuevas tie-

${ }_{5}$ Fray Toribio de Benavente o Motolinía, Memoriales o Libro de las cosas de la Nueva España y de los naturales de ella, México, UNAM, 1971, pp. 34-35. 
ras, cllo se debió a que acababan de pasar por la reforma impucsta por el cardenal Cisneros que las convirtió en instrumontos idóneos. En el caso de los franciscanos, esta reforma impucsta por el cardenal -que también era franciscano- coincidió con una necesidad interna de la orden de volver a sus fuente's. Casi todos los evangelizadores de la Nueva España procedian de la provincia reformada de San Gabriel de Extremadura que se caracterizó por su observancia a la regla de San Francisco. Y esta regla no es, de hecho, otra cosa que el evangelio convertido en norma de vida. Así pues, lo que pretendían inculcar en los neófitos era la imitación de Cristo, una religiosidad interior que "se cifra en la sincera humildad, paciencia, temor de Dios y en la divina sabiduría". Si se quiere, se puede ver en ello la influencia de Erasmo, aunque quizá se trate más bien de una convergencia. Sea de ello lo que fuere, la actitud liranciscana es comprensible y loable, y por ello resulta necesarria la insistencia en que, como dice el catecismo de fray Maturino Gilberti,

no sc adora ninguna imagen aunque sea el crucifijo, ni tampoco a Santa María... y aunque delante del crucifijo, de rodillas, sc adora, no empero se adora el crucifijo porque solamente es hecho de palo, pero a Dios mismo nuestro Señor que está en el ciclo. ${ }^{6}$

Los exabruptos de Sahagún y Bustamante contra el culto guadalupano encajan perfectamente dentro de esta manera de comprender la labor apostólica. Lo extraño no es que se hayan dado, sí lo sería en cambio que hubiesen callado. Pues a los ojos de estos misioneros, la actitud contraria, es decir, admitir que los neófitos indígenas dieran preferencia a una advocación mariana sobre otra, a un santo sobre otro o a una determinada imagen significaba, ni más ni menos, que abrir el camino a una aberración total: la mezcla del culto al único Dios con el servicio al demonio.

Tal era, poco más o menos, la situación del guadalupanis-

"Citado por Robert Ricard, La conquista espiritual de México, México, Ed. Jus, 1947, p. 217. 
mo en la segunda mitad del siglo XVI, sostenido como vimos, por la jerarquía eclesiástica y el clero secular y rechazado por un grupo de frailes, cuando hizo su aparición en el escenario novohispano una nueva orden: la Compañia de Jesús, que provocaría un cambio radical.

Si la formación de los franciscanos observantes los predisponía contra cualquier culto nuevo, la formación del jesuita lo predisponía a favor. Si al franciscano lo inquietaba la formación religiosa del indigena, al jesuita le preocupaba la formación intelectual del criollo.

Pero vayamos por partes. Tras varios intentos fracasados -el primero lo hizo don Vasco de Quiroga ante el propio Ignacio de Loyola, el segundo lo emprendió don Alonso de Villaseca ante Francisco de Borja-, los primeros miembros de la Compañía entraron a la ciudad de México la noche del 26 de septiembre de 1572. Su llegada obedeció a la súplica que la ciudad de México y el virrey de la Nueva España, don Martín Enriquez, habian enviado a Felipe II en la que decían que los necesitaban "de maestros de leer y escribir, de latinidad y demás ciencias" y para "reducción de las naciones gentiles". El rey parece haber hecho caso omiso de la necesidad de maestros en la ciudad, puesto que su petición al provincial de Castilla sólo menciona "la instrucción y conversión de los naturales". De hecho, a pesar de su corta vida (la bula de aprobación es de 1540), la Compañía se había distinguido ya tanto en el terreno de la educación como en el de la conversión de infieles. A pesar de ello, el propósito de Felipe II de emplear a los jesuitas para la evangelización había de verse frustrado por un tiempo. Fuera por la presión de los habitantes de la capital que encontraban a la juventud "tan necesitada de doctrina y buena educación contra la ociosidad y regalo nacidos de la abundancia y riqueza de esta tierra"," fuera porque, como dice el padre Ayuso, el superior de la misión, Pedro Sánchez, no conocía más vida que la de los colegios, el hecho fue que los jesuitas decidieron encauzar sus esfuerzos a la educación de los novohispanos. Lo que había de ser decisivo para éstos, para el guadalupanismo y, en última instancia, para México.

7 Anónimo, Relación breve, México, 1602, p. 25. 
Como ya he dicho, esta dedicación jesuística a la enseñanza tenía ya antecedentes. Pues si bien en un principio, Ignacio de Loyola parece haber titubeado en cuanto al fin al que dedicaría a su pequeña tropa, muy pronto, ante los triunfos cada vez mayores del protestantismo, el fundador vio claramente la misión de su orden: dirigir la conciencia de los poderosos por medio de la educación y la confesión, ya que en aquel tiempo de ellos dependian todas las resoluciones, aun en materia de fe. Asi grandes territorios alemanes y aun paises enteros se habian perdido para la Iglesia, por la decisión del gobernante de abrazar el protestantismo. Había pues que educar a los príncipes y grandes de la tierra de tal manera que la fe en el dogma no contradijera el afán de conocimiento racional, ni los anhelos humanistas de la época. Una educación que, mediante el ejercicio de la voluntad, en el que tanto insiste la Compañía, capacitara al alumno para su vida futura. La idea de Ignacio, al encaminar a su minima compañía a la educación de las clases superiores, parece haber sido que el vulgo seguiría más o menos dócilmente el ejemplo que el gobernante les diera. Por otra parte, el caso de Alemania que fue en cierta medida, ol campo de experimentación jesuita en materia de educación, los alertó de inmediato sobre el despertar de una conciencia nacional y su estrecha relación con el rechazo popular a la hegemonia del papado. Lutero había entregado al pucblo la Biblia en alemán, y los predicadores protestantes usaban también la lengua vernácula en la nueva liturgia. En todo cl territorio protestante, no sólo se había roto la ecumene cristiana, sino que había sido reemplazada por una identificación cada rez inayor entre el carácter naciónal y la nueva expresión del sentimiento religioso. Al enfrentarse a este hecho, los jesuitas estaban atados por la imposibilidad de cambiar la liturgia católica, pero lo que sí podian hacer e hicieron de hecho fue encauzar esa naciente conciencia nacional hacia símbolos o cultos religiosos nacionales. Los jesuitas promovieron así las peregrinaciones y el culto en los santuarios populares y aun se ha llegado a decir que en algunos casos - por ejemplo, el San Juan Nepomuceno, confesor de la reina de Bohemia, y declarado patrón de esta nación-inventaron tal culto.

$\mathrm{Al}$ parecer todo esto nos ha llevado muy lejos de la Nueva 
España, pero lo cierto es que la experiencia adquirida en Europa iba a ser determinante en la labor de los jesuitas que, iniciada a fines del siglo XVI, se mantendría sin cambios mayores hasta la expulsión de la Compañía en 1767. Mencioné antes que uno de los vecinos de México nás interesados en el establecimiento de los jesuitas fue don Alonso de Villaseca, por entonces el hombre más rico de la Nueva España. A su llegada no sólo les dio la primer limosna que recibieron en México, sino también los solares en que edificaron su primera casa y no contento con ello y con las continuas dádivas, se declaró en 1577 como fundador del Colegio Máximo de San Pedro y San Pablo. Pero a más de rico, el señor de Villaseca era un ferviente guadalupano, tan devoto que "ha quedado la noticia cierta de una imagen de plata vaciada con su peana y corona doradas" que ofreció como ex-voto al santuario, en el cual se veló su cuerpo por tres dias, cuando lo trajeron de sus minas de Ixmiquilpan a enterrar a México.

Otro gran devoto de la Guadalupana fue el licenciado Juan de Tovar, racionero de la catedral y secretario del cabildo, gran nahuatlato, que fue el segundo mexicano que pidió y obtuvo ser recibido en la Compañia.

Es muy posible que los jesuitas fueran atraidos al culto guadalupano por su bienhechor, si bien no debe perderse' de vista que tal culto cra ya muy popular y estaba respaldado por la jerarquia eclisiástica, como también que la Compañia hacía sicmpre todo lo posible por acomodarse a todas las peculiaridade's del lugar en que se encontrase.

Seguía en ello el consejo de Francisco Javier a sus sucesores: "Esforzáos desde el primer día por saber qué clase de negocios se tratan en cada sitio, cuáles son las costumbres y usanzas del pais y de los alrededores..." tan al pie de la letra lo siguieron que lueron comerciantes entre los comerciantes, soldados entre los soldados, sabios entre los sabios y, al llegar a China... pues se hicieron mandarines, con gran escándalo de la Sagrada Congregación de Ritos.

De un modo u otro, lo cierto es que al construirse el noviciado en abril de 1573, es decir apenas siete meses después de su llegada, se puso en la capilla (según las noticas un tanto con- 
fusas del padre Florencia, ${ }^{8}$ un altar de Nuestra Señora de Guadalupe, lo que, andando el tiempo, se convertiría en característica de las iglesias y capillas de la Compañía.

A la fundación del primer colegio siguió rapidísimamente la de tres escuelas más: San Bernardo, San Miguel y San Gregorio en la capital. A ellos se añadieron antes de finalizar el siglo los de Pátzcuaro, Oaxaca, Puebla, Veracruz y Guadalajara y principios del siglo XVII los había también en Zacatecas, Durango, Mérida y San Luis Potosí, Querétaro y Guanajuato. No hubo, pues, ciudad virreinal importante que careciera de un colegio jesuita, lo que quiere decir que en sus manos quedó la educación de los jóvenes novohispanos; pero no de todos, sino al igual que en Europa de aquellos que pertenecian a las clases más acaudaladas. Pero el ejemplo europeo no sólo sirvió para la selección de los alumnos; la educación debía ser exactamente igual en todos los colegios y el superior general de los jesuitas se preocupó desde 1584 por formar una comisión que estableciera la regla que debía seguirse en todos los colegios. Quince años más tarde se editó la Ratio studiorum que regiría toda la educación jesuita. Ahora bien, ¿ de qué tipo era la educación? La Ratio atiende preferentemente a la educación formal del alumno, procurando, ante todo, formar al hombre completo, desarrollando armónicamente todas sus facultades y. colocándolo en situación de poder dedicarse más adelante a la actividad elegida. En palabras de un jesuita moderno, el padre Mariano Cuevas, esta educación "estribaba por completo en el orden sobrenatural, en los principios fijos de la fe y de la piedad que los jesuitas tenemos como base única e insustituible de toda educación y como elemento necesario para que la juventud no se precipite en la más abominable corrupción". ${ }^{9}$ En la práctica diaria, estos preceptos dieron una organización peculiar. En todos los establecimientos jesuitas la enseñanza se dividía en tres grados: la clase elemental de gramática, en la que se enseñaba la lengua latina y se ejercitaba la memoria; el grado siguiente era el de retórica en el que se buscaba desarrollar la

${ }^{8}$ Francisco de Florencia, S.J., Historia de la Provincia de la Compañía de Jesús de la Nueva España, México, 1694, p. 149.

${ }^{9}$ Mariano Cuevas, S.J., Historia de la Iglesia en México, 5 vols., El Paso, Texas, 1921-1929, vol. IV, p. 153. 
agilidad de pensamiento y se leía de preferencia a los autores latinos. El último grado, la dialéctica, estaba destinado a capacitar a los jóvenes para la meditación justa de argumentos contradictorios y acostumbrarlos a que las contradicciones no habían de resolverse por afirmación o negación, sino elevándolas a una unidad superior. De todo esto se desprende una perfecta jerarquización de la enseñanza, pero, a decir verdad, no encuentro en ella rada que la haga especialmente adecuada para quicnes habian de tener en sus manos decisiones politicas y religiosas de la mayor importancia. Quizá el secreto esté en las tantas reces nombrada "educación de la voluntad", "formación del carácter", que debia capacitarlos para ocupar el pues10) al que su nacimiento los llamaba. El problema está en que los maestros de la Compañia no parecieron dàrse cuenta nunca de que precisamente por su nacimiento, a los jóvenes criollos que cducaban se les negaba toda participación en las decisiones de gobierno. Formaron así generaciones sucesivas de jóvene's celucados para las inás altas responsabilidades y que nunca llegarian a tenerles.

A la frustración de la juventud criolla le quedó un solo desahogo, el culto guadalupano cuyos promotores habian sido lambién los jesuitas. Todo lo que España les negaba, les cra entregado con creces por el guadalupanismo. El sentimiento de minusialía provocado por la actitud de los gachupines quedaba más que compensado por el fasor que Maria habia concediclo a su patria. Y cuando, como en tantos casos, los criollos aninan a esta condición la del sacerdote jesuita. El guadalupanismo no encuentra ya barreras. A la Virgen de Guadalupe so le atribuyen todos los prodigios y todas las mercedes. La terminación de una peste hizo decir al jesuita Alegre: "parece que e angel exterminador no esperaba más que esta resolución /es decir, jurar a la Virgen de Guadalupe como patrona/ para envainar/su/ espada". ${ }^{10}$ Otro jesuita, Francisco Javier Carranza, crevó posible La transmigración de la Iglesia a Guadalupe (1749) y, scguin se dice, el primer relato impreso sobre la Guadalupana, Imagen de la lirgen María Madre de Dios de Guadalupe (1648), del

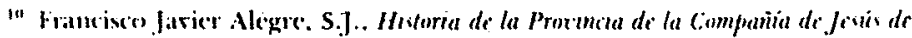

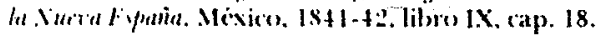


presbítero oratoriano Miguel Sánchez, se basa en un manuscrito atribuido a don Antonio Valeriano que conservaban los jesuitas como herencia de Sigüenza y Góngora. Este a su vez no sólo fue de notoria condición jesuíticá, sino que cántó juntas la gloria de María y de México en su Primavera indiana:

María soy, de Dios omnipotente humilde madre, virgen soberana, antorcha cuya luz indeficiente Norte es lucido a la esperanza humana;

Ara fragante en templo reverente México erija donde fue profana morạda de Plutón, cuyos horrores. tala mi planta en tempestad de flores.

El mismo camino sigue el poema del padre Francisco de Castro intitulado Octava maravilla:

¡Oh feliz, exclamé, tierra, si hay tierra, de lauros fértil y erial de guerra...!

¿Oh mundo, mundo, mundo sin tragedia necio es el que, pudiendo, no te asedia!

Pero, volviendo a los primeros relatos escritos sobre la tradición, poco después (1660) de aparecido el libro de Sánchéz, un jesuita, Mateo de la Cruz, escribió una segunda versión destinada a un público más amplio, despojada por ello de todas las referencias eruditas que prodigó el oratoriano.

Fue tanta la devoción de la Compañía de Jesús hacia la Guadalupana que, de acuerdo con las investigaciones realizadas por Pilar Gonzalbo para su estudio sobre la influencia de los jesuitas en la sociedad novohispara,", cuando menos "diecisiete jesuitas vieron impresos sus sermones guadalupanos, trece escribieron historias sobre el asunto y muchos más cantaron en verso sus alabanzas". Entre estos últimos vale la pena mencionar al padre Lucas Anaya - uno de los expulsos- quien por estar enfermo tardó cuatro años en salir de la Nueva Espa-

". Pilar Gonzalbo, "La educación popular de la Compañía de Jesús en la Nueva España”, tesis de doctorado inédita. 
ña, años que pasó encerrado y dedicado a la poesía. Su larguísimo poema heroico de mil octavas que circuló manuscrito tenía el barroco título de "Verdadera metamorfosis en que las flores de la tierra se transformaban en una imagen del cielo, la verdaderà efigie de María, Señora Nuestra de Guadalupe, que el día martes 12 de díciembre de 1531 quedó estampada en el débil, tosco y grosero, pero felicísimo ayate del dichosísimo neófito Juan Diego". No menos barrocos y desbordantes son los títulos de otras obras guadalupaná debidas a los jesuitas criollos. Así, por ejemplo, el padre Francisco Javier Lazcano escribió el Guadalupano zodiaco para recibir de la escogida como el sol Maria Señora Nuestra los más propicios influjos, obra en la que prosigue el tema desarrollado un año antes en su Sermón panegírico, donde afirma que Dios manifestó su predilección por México al crear una nueva forma de evangelizar, por el pincel y no por la pluma (la imagen de Guadalupe es "cartilla" para los indios), por María antes que por Jesús, por la vista antes que por el oído, por la Virgen misma y no por los apóstoles. ${ }^{12}$

El último de los que Francisco de la Maza llamó "evangelistas guadalupanos", el jesuita Francisco de Florencia, no se quedó atrás en cuanto a título barroco, pues llamó a su libro La estrella del norte de México aparecida al rayar el día de la luz evangélica en este Nuevo Mundo en la cumbre del cerro del Tepeyac, orilla del mar texcocano .... Obra devota si las hay, llena de detalles tiernos e ingenuos que por ello mismo llegó a todo el pueblo y es, hasta hoy, el relato ejemplar de la tradición guadalupana.

Tan devoto fue este jesuita que a él se debe la aplicación de la frase bíblica: Non feci taliter omni nationi, al hecho guadalupano, frase que había de convertirse en lema del culto y en expresión soberbia del nacionalismo criollo.

Fue también el padre Florencia quien llevó a Roma, en 1666 , las súplicas del cabildo metropolitano para que se concediera un oficio litúrgico propio en honor de la Virgen de Guadalupe. Roma no fue propicia, aunque sí señaló el 12 de diciembre para la fiesta guadalupana, que fue desde entonces fecha fundamental en la vida de los mexicanos. Desde luego, los

12 Francisco Javier Lazcano, S.J., Sermón panegírico, México, 1759, p. 8, citado por Gonzalbo. 
criollos no desistieron de su empeño, pues su propio ser les iba en ello. Y el apogeo del guadalupanismo -elemento central de su vida y sin el cual, como dice Jorge Alberto Manrique, "la historia de la Nueva España no habría sido la misma"- llegó cuando, ya jurada la Guadalupana como patrona de la Nucra Espana cntre los años 1737 y 1740 , el procurador de la causa, el padre Juan Francisco López, miembro de la Compañía de Jesús, logró que la Santa Sede diera la confirmación del patronato y concedicra la aprobación del oficio litúrgico en 1754 .

Poco tiempo habian de gozar su triunfo los jesuitas criollos, puesto que apenas trece años después fucron obligados a expatriarse.

Su último acto "oficial" en ticra mexicana scria la súpli(a al virrey de la Nueva España para que los desterrados, "pasando por Nuestra Señora de Guadalupe, se encomienden! despidan de esta divina Señora..."

Como ya se dijo, el padre Anaya logró escribir su poema codavia en tierras mexicanas, los otros expulsos prosiguicron su labor en el desticro a fin de difundir el culto guadalupano en Europa y acallar a la vez su nostalgia. El padre Andres de la Fucoutc publicó en Faenza (1773) su Guadalupama Mariae l'irgimis Imago quae dexici colitur carmine descripla, y cn la misma ciudady lecha salió a luz ol himno Inmaculatae V'irginis Deiparae Simcta llaria de Guadalupe, del padre Pedro Gallardo. Otro jesuita, Josc Mariano Gondra, no sólo dedicó poemas a la Virgen, sino cue tradujo al italiano la Maraxilla americana del pintor Miguel Cabrera. No habia de ser menos en esta empresa el más notable de los expulsos, Francisco Javier Clavijero, pues también el se sintió llamado a difundir el mayor timbre de gloria de su patria y escribió un Breve ragguaglio della rinommata Imagine di Giuadalupe del Messico. ${ }^{13}$

Tras este breve repaso de la devoción crriolla y jesuita por la Guadalupana es fácil asentir a lo dicho por Francisco de la Maza cn su tan citado libro: "suponer en Hidalgo /y no se olvide que fue alumno de los jesuitas/ una gran ocurrencia politica al enarbolar a la Guadalupana en Atotonilco es ignorar que en la conciencia de todos los mexicanos estaba ya plenamente cla-

1s Publicada en Cesena, 1782. Este texto mo ha sido (raducido havas ahona. 
ra, cuando menos desde mediados del siglo XVIII, que la Guadalupana era, además de un retrato único de la madre de Dios, un símbolo patriótico para reconocer y diferenciar a México del resto del mundo, que eso es una bandera"."14

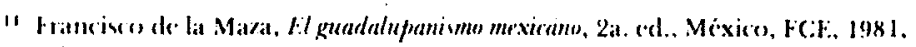
p. 151. 
Elsa Cecilia Frost

\section{Mínima Bibliografia el Guadalupanismo}

1648 Imagen de la Virgen María Madre de Dios de Guadalupe, milagrosamente aparecida en in ciudar de México, del presbitero Miguel Sánchez. Es el primer texto impreso.

1649 Huei tlamahuizoltica omonexiti ilhuicac tlatoca ihualpilli Sancta Maria /EI gran acontccimiento con que se apareció la Señora Reina del Cielo Santa Maria/, de Luis Lasso de la Vega, quien afirma en el "Prólogo" ser él quien escribió "'en náhuatl el milagro". Sin embargo, algunos lo consideran una simple traducción al náhuatl del libro de Sánchez, en tanto que otros lo atribuyen a don Antonio Valeriano, célebre alumno del no menos célebre Colegio de Santa Cruz do Tlatelolco, en el que fuera discípulo de fray Bernardino de Sahagún. Esta obra incluye el "Nican Motecpana", atribuido éste a don Fernando de Alba Ixtlilxóchitl.

1688 La estrella del Norte de México aparecida al rayar el dia de la luz evangélica en este N'uer'o Mundo..., del jesuita Francisco de Florencia.

1746 Escudo de armas de México, de Cayetano Cabrera y Quintero.

1756 Maravilla americana, del pintor Miguel Cabrera.

1797 Pensil americano, florido en el rigor del invierno, la imagen de María Santísima de Guadahupe, de Ignacio Carrillo y Pérez; publicado "a instancias de algunas pcrsonas", como respuesta al sermón de fray Servando Teresa de Mier.

1817 Memoria sobre las apariciones de Nuestra Señora de Guadalupe de México, del español Juan Bautista Muñoz.

1871 Relación histórica de la admirable aparición de la Virgen Santísima Madre de Dios, bajo el título de Nuestra Señora de Guadalupe, de Anastasio Nicoselli.

1875 Felicidad de México en el principio y milagroso origen del santuario de la Virgen Maria de Guadalupe, de Luis Becerra Tanco, el terceero de los "evangelistas guadalupanos". Es la primera obra que intenta dar una explicación de la imprimación en el ayate. Escrita en 1675 apareció póstumamente.

1889 Informaciones sobre la milagrosa aparición de la Santísima Virgen de Guadalupe recibidas en 1966 y 1723, fueron publicadas por el presbítero y bachiller Fortino Hipólito Vera.

1896 Carta acerca del origen de la imagen de Nuestrá Señora de Guddalupe, esta discutidísima carta es la respuesta que don Joaquín García Icazbalceta dio a instancias del arzobispo de México, don Pelagio Antonio de Labastida y Dávalos.

1930 Album histórico guadalupano del IV centenario, de Mariano Cuevas, S.J.

1931 La aparición de Santa María de Guadalupe, del licenciado Primo Feliciano Vázquez.

1946 Cuestiones históricas guadalupanas, de José Bravo Ugarte, S.J.

1953 El guadalupanismo mexicano, espléndida y discutida tesis doctoral de Francisco de la Maza.

1974 Quetzalcóatl et Guadalupe, polémico texto de Jacques Lafaye.

1978 El culto guadalupano del Tepeyac, bello estudio de fray Fidel de Jesús Chauvet.

1981 El heterodoxo guadalupano, admirable estudio en tres volúmenes, hecho por Edmundo O'Gorman, sobre el guadalupanismo de fray Servando Teresa de Mier.

1981 Album conmemorativo del 450 aniversario de las apariciones, bellísimamente ilustrado y ejemplarmente impreso. 